New Methods of Analytical Chemistry

Second edition. By R. Belcher and C. L. Wilson. In association with T. S. West. Pp. $\mathrm{xv}+366$. (London: Chapman and Hall, 1964.) $60 s$.

7 Ther HE United Kingdom can boast of only three university professors of analytical chemistry, and when they all collaborate in the revision of a well-known book it is certain that the work will possess that sartor resartus quality which signposts an improvement in its scientific and didactic value. This expectation is fully borne out by this second edition.

The first chapter deals individually with the more common titrimetric acid-base standards and then considers those of more recent origin, for example 4-aminopyridine for acids and sodium hydrogen diglycollate for bases. Oxidation-reduction standards such as cupric oxide or barium thiosulphate are also briefly considered.

Indicators of all types, chemiluminescent, screened, redox, metallochromic, etc., are all lucidly dealt with in the second chapter. A detailed account of titrant usages then follows, for example the use of sodium chlorite; ferricyanide procedures; potentiometric titrations of hydrazine; use of $N$-bromosuccinimide, etc.

Newer organic and inorganic precipitants form a most valuable section of this book, although they can only receive brief mention here. Selected spectrophotometric methods from recent literature are presented in much detail, for example, the arsenazo method for hafnium; and the pyrogallol red procedure for silver ion. Precipitation from homogeneous solution receives adequate treatment, four specific procedures being mentioned. The powerful techniques of solvent extraction receive full coverage, simultaneous extraction and direct analysis being sometimes possible.

The final chapter presents a survey of miscellaneous analytical methods which will titillate the palates of both the classical and the more sophisticated analyst. The gravimetric determination of fluoride and the titrimetric determination of barium sulphate are typical of the many analyses lucidly covered in this section.

This edition of New Methods of Analytical Chemistry, even more than its predecessor, will be a welcome addition to the libraries of analysts everywhere. The lecturer, teacher and practising analyst will all derive much instruction and help from this up-to-date authoritative discussion and presentation of the newer reagents and of recent methods.

D. T. Lewis

\section{Coulomb Wave Functions}

By A. R. Curtis. (Royal Society Mathematical Tables, Vol. 11.) Pp. $x x x v+209$. (Cambridge: At the University Press, 1964. Published for the Royal Society.) 80s. net.

COULOMB wave functions arise in the solutions of Schrödinger's equation for an electron in a central field. The U.S. National Bureau of Standards published tables of these functions in 1952 (Applied Mathematics Series No. 17), and other tables are also known.

In 1950, the late Prof. D. R. Hartree and others proposed to the Royal Society Mathematical Tables Committee the preparation of tables of these functions, and the present volume is the outcome of their proposals. An attempt was made to choose solutions of the differential equation which are not only mathematically linearly independent but also numerically distinct, and at the same time to produce tables which are readily interpolable in the energy parameter. These two requirements are not entirely compatible, and the final choice of solutions is to some extent a compromise.

Coulomb Wave Functions contains a mathematical introduction, a useful collection of formulae concerning the selected standard solutions, instructions for the use of the tables, and a bibliography. The tables themselves give values of the selected solutions of the differential equation $y^{\prime \prime}+\left[a+2 x^{-1}-L(L+1) x^{-2}\right] y=0$ for $L=0$,
1,$2 ;-2 \leqslant a \leqslant 2$; and $0 \leqslant x<\infty$. For $x \geqslant 10, x^{-1}$ is used as the tabular argument. The tables are reproduced photographically from sheets prepared on a card-operated typewriter.

A. ERdélyi

\section{Chemotaxonomie der Pflanzen}

Fine übersicht über die Verbreitung und die Systema. tische Bedeutung der Pflanzenstoffe. Von Prof. R. Hegnauer. Band 3: Dicotyledoneae: AcanthaceaeCyrillaceae. (Chemische Reihe, Band 18.) Pp. 743. (Basel und Stuttgart: Birkhäuser Verlag, 1964.) $123 \mathrm{Sw}$. francs.

WITH Volume 3 of Chemotaxonomie der Pflanzen begins the treatment of the large group of Dicotyledoneae which is covered as far as Cyrillaceae. The first few chapters contain a survey of the chemistry of alkaloids common in this group. They are subdivided into protoalkaloids or biogenic amines, pseudoalkaloids like terpenes, purines, and derivatives of nicotinic acid, and into alkaloids themselves. The pathways of biosynthesis of larger structures from simple amino-acids are schematically outlined.

The Dicotyledoneae include many plants of great medical and toxicological interest, of which a few examples may be mentioned. To the Apocynaceae belong compounds of the yohimbine-, reserpine-, strychnine-, and cantharidin-types, and strophanthin. Quaternary ammonium bases with curariform action are present in Capparidaceae, and salicin is found in Caprifoliaceae. Hallucinogens are discussed in connexion with several families; Lophophora williamsii, the Mexican peyote, is a well-known example, and for Cannabis sativa the chemical relationship between antibiotic and bactericidal actions and intoxicating effects is outlined. The pathways of synthesis of norephedrine in Catha edulis may be similar to those of ephedrine in Ephedra. Chinese and Japanese medicine uses plants of the Asarum family, the identity of which is not fully established. Derivatives of the anthelmintic pelletierine have been found in the Crassulaceae.

Of general interest are the Asclepiadaceae which contain arrow poisons, and the Annonaceae in the seeds, leaves and roots of which substances of an unknown type act as contact poisons against aphides.

Though the literature is considered until the end of 1963 , the author states that Volume 3, unlike its predecessors, does not contain a complete survey of the known facts, since for some families, like the Apocynaceae, the phytochemical literature is very large and readily available in modern standard works. Even so, the volume presents in a clear manner a wealth of information on a field of wide interest.

L. WISLICKI

\section{Scientists as Writers}

Edited by James Harrison. Pp. 206. (London: Methuen and Co., Ltd., 1965.) 21s. net.

SCIENTISTS as Writers is essentially an annotated anthology of prose passages written by scientists, mostly of the present century, arranged around eleven themes, including the nature of the univorse, of matter, of life, of mind and of science, evolution and man, the laws of chance, science and art, and science and religion. They are linked by explanatory notes and comments, and there are a few suggestions for further reading. The book is intended for use in general courses in sixth forms and elsewhere, to further both the command of English and the broader understanding of science. While it illustrates admirably that scientists can and do write about their work lucidly and in impeccable English, it seems to achieve its second purpose of interpretation even more effectively than the selection of similar excerpts edited by S. Rapport and H. Wright and published two years ago under the title Science: Method and Meaning. 